\title{
Crescimento e nutrição de mudas de abacaxizeiro 'Imperial' associadas com o fungo Piriformospora indica e aplicação de herbicidas
}

\author{
Growth and nutrition of 'Imperial' pineapple nursery \\ plants associated with the fungus Piriformospora indica and \\ herbicide application
}

\author{
Lana Ivone Barreto Cruz'; Maria do Céu Monteiro $\mathrm{Cruz}^{2 *}$; Guilherme Dumbá \\ Monteiro de Castro ${ }^{3}$; Miriã Cristina Pereira Fagundes ${ }^{1}$; José Barbosa dos Santos ${ }^{2}$
}

\section{Resumo}

\begin{abstract}
A baixa oferta de mudas sadias e com qualidade tem sido um obstáculo para o crescimento da abacaxicultura no Brasil. A pesquisa foi realizada com o objetivo de avaliar a associação micorrízica, o crescimento e absorção de nutrientes em mudas micropropagadas de abacaxizeiro 'Imperial' inoculadas com o fungo Piriformospora indica em cultivo com a aplicação de herbicidas. Foi utilizado o esquema fatorial $2 \times 4$, sendo os fatores duas inoculações: mudas inoculadas com o fungo $P$. indica e sem inoculação e quatro doses de herbicidas: $0 ; 1,5 ; 3,0$ e $6,0 \mathrm{~L} \mathrm{ha}^{-1}$ para o ametryn, $0 ; 1,6 ; 3,2 ; 6,4 \mathrm{~L} \mathrm{ha}^{-1}$ para o diuron e $0 ; 0,4 ; 0,8$ e 1,6 $\mathrm{L} \mathrm{ha}^{-1}$ para o sulfametrazone, distribuídos no delineamento inteiramente casualizado, com três repetições. As doses dos herbicidas foram aplicadas ao substrato antes do plantio das mudas. A inoculação com o fungo $P$. indica foi feita no momento do plantio, colocando-se no substrato discos de micélio de $5 \mathrm{~mm}$, contendo estruturas fúngicas. Aos 150 dias após a inoculação foi feita a análise da colonização micorrízica, dos teores de N, P e K e do crescimento das mudas. Os dados foram submetidos à análise de variância, regressão polinomial e comparação de médias, a $5 \%$ de probabilidade. Foi observada a associação do fungo $P$. indica com as mudas de abacaxizeiro 'Imperial' com a aplicação de todos os herbicidas. As mudas associadas com o fungo apresentaram maiores teores de nutrientes e crescimento. A aplicação dos herbicidas em doses elevadas interferiu no crescimento e na absorção de nutrientes pelas mudas de abacaxizeiro micorrizadas.
\end{abstract}

Palavras-chave: Ananas comosus, associação micorrízica, estado nutricional

\begin{abstract}
The low supply of healthy and quality nursery plants has been an obstacle to the growth of pineapple crop in Brazil. The research was carried out with the aim of evaluating mycorrhizal association, growth and nutrient uptake of 'Imperial' micropropagated pineapple plants inoculated with the fungus Piriformospora indica in cultivation with herbicide application. The $2 \times 4$ factorial scheme was used, being the factors the two inoculations: inoculated nursery plants with the fungus $P$. indica and without
\end{abstract}

\footnotetext{
1 Mestres em Produção Vegetal, Programa de Pós-Graduação em Produção Vegetal, Universidade Federal dos Vales do Jequitinhonha e Mucuri, UFVJM, Campus JK, Diamantina, MG. Bolsista da CAPES. E-mail: lanabarretocruz@gmail.com; miria.agro@yahoo.com.br

2 Profs., Programa de Pós-Graduação em Produção Vegetal, UFVJM, Campus JK, Diamantina, MG. E-mail: mariceu@ufvjm.edu. br; jbarbosasantos@yahoo.com.br

3 Discente do Curso de Graduação em Agronomia, UFVJM, Campus JK, Diamantina, MG. Bolsista de IC FAPEMIG. E-mail: dumba12@hotmail.com

* Autor para correspondência
} 
inoculation and four doses of herbicides: $0,1.5,3.0$ and $6.0 \mathrm{~L} \mathrm{ha}^{-1}$ for ametryn, $0,1.6,3.2,6.4 \mathrm{~L} \mathrm{ha}^{-1}$ for diuron and $0,0.4,0.8$ and $1.6 \mathrm{~L} \mathrm{ha}^{-1}$ for sulfametrazone distributed in a completely randomized design with three replications. The doses of herbicides were applied to substrate before planting. The inoculation with the fungus $P$. indica was made at the time of planting, placing in the substrate $5 \mathrm{~mm}$ mycelial discs containing fungal structures. At 150 days after inoculation evaluations were made by analysis of colonization, determination of N, P and K levels and of nursery plants growth. Data were subjected to analysis of variance and regression. The association of fungus $P$. indica with 'Imperial' pineapple nursery plants was observed with the application of all herbicides. 'Imperial' pineapple nursery plants associated with $P$. indica fungus showed higher levels of nutrients and growth. The use of herbicides in high doses interfered in growth and nutrient uptake by mycorrhizal pineapple nursery plants.

Key words: Ananas comosus, mycorrhizal association, nutritional status

\section{Introdução}

A produção nacional de mudas de abacaxizeiro tem sido caracterizada pela baixa oferta de material de qualidade sanitária e da falta de um sistema eficiente de obtenção de mudas. Mudas sadias e de boa qualidade podem ser obtidas por meio da cultura de tecidos. No entanto, utilizando-se este método, as mudas necessitam passar por um período de aclimatização até atingirem o tamanho adequado para o plantio definitivo no campo. Esse período é variável e depende do substrato e da nutrição, podendo durar de 6 a 10 meses (BARROSO et al., 2003), o que eleva o custo de produção das mudas, inviabilizando esta atividade por parte dos viveiristas.

A associação de fungos micorrízicos com o abacaxizeiro é de grande importância e interesse, pois, estimula o crescimento da muda pela melhoria na absorção de nutrientes, devido à expansão da zona de absorção da raiz, possibilitando a produção mais precoce. Essa técnica tem sido efetiva na produção de mudas, permitindo reduzir o tempo de formação de mudas de várias espécies frutíferas, entre elas de mamoeiro (MARTINS; GONÇALVES; SOARES, 2000), maracujazeiro-doce (ANJOS et al., 2005) e abacaxizeiro 'Smooth Cayenne' (SANTOS et al., 2011). Isso ocorre porque os fungos penetram nas raízes, atuando como um sistema radicular adicional, o que contribui para aumentar a área radicular efetivamente ocupada no solo e melhorar a capacidade das plantas na absorção de nutrientes, em especial o fósforo, beneficiando o crescimento e, consequentemente, o vigor e a produtividade (MOREIRA; SIQUEIRA, 2006).

Dentre os fungos micorrízicos, encontra-se o Piriformospora indica, que coloniza as raízes, cresce inter e intracelularmente, promove a absorção de água e nutrientes, permite que as plantas sobrevivam sob condições de estresse e ainda confere resistência sistêmica a toxinas, íons de metais pesados e a organismos patogênico, estimulando o crescimento (OELMÜLLER et al., 2009); além disso, esse fungo tem facilidade de cultivo em meio sintético (BAGDE; PRASADAND; VARMA, 2010).

Oestabelecimentodasmudas nocampodependerá de outros fatores, não diretamente empregados para a nutrição das plantas, como o uso de agroquímicos para o controle de plantas daninhas. A utilização de herbicidas é crucial para evitar a competição por recursos do meio e favorecer o desenvolvimento da cultura, pois o abacaxizeiro é uma cultura de crescimento lento e de pequeno porte. Esses fatores indicam a necessidade de manter o abacaxizal livre da competição com plantas daninhas, sobretudo nos primeiros meses após o plantio. Os herbicidas utilizados para esse manejo, a exemplo do ametryn e o diuron, agem rapidamente por interferem na síntese de clorofila, alterando o funcionamento dos cloroplastos (FAYEZ, 2000) e o sulfentrazone está relacionado com a inibição da produção de clorofila pelo bloqueio da rota (DUKE et al., 1991).

Entretanto, a opção por este método de controle requer estudos sobre a seletividade de herbicidas, 
já que os produtos seletivos utilizados na abacaxicultura podem exercer efeito negativo sobre microrganismos benéficos às plantas, a exemplo dos fungos micorrízicos, pois o estabelecimento da simbiose micorrízica é determinado por fatores edafoclimáticos e aspectos da relação fungo-planta, com a utilização de diferentes espécies e ou isolados de fungos micirrízicos arbusculares, resultando em respostas diferenciadas por parte do hospedeiro (CAVALCANTE et al., 2002).

As duas técnicas são vantajosas para o cultivo do abacaxizeiro, os fungos micorrízicos pelos benefícios proporcionados a cultura, contribuindo para o rápido crescimento das mudas e melhor estabelecimento no campo após o transplantio, e os herbicidas por ser a alternativa para reduzir os custos de produção no controle de plantas daninhas (MAIA et al., 2012), No entanto, os efeitos da utilização de herbicidas sobre os organismos presentes no solo ainda são pouco conhecidos, e alguns pesquisadores apontam para a necessidade de estudos sobre a ação dos diversos agroquímicos utilizados na agricultura, a fim de se entender os processos biológicos que são alterados, visando compreender e utilizar, de forma benéfica, as novas interações surgidas no sistema (ROSA et al., 2010).

Diante disso, esta pesquisa foi realizada com o objetivo de avaliar a associação micorrízica, crescimento e absorção de nutrientes de mudas micropropagadas de abacaxizeiro 'Imperial' inoculadas com o fungo Piriformospora indica em cultivo com a aplicação de herbicidas.

\section{Material e Métodos}

O trabalho foi conduzido em casa de vegetação no Setor de Fruticultura da Universidade Federal dos Vales do Jequitinhonha e Mucuri, em Diamantina, MG, utilizando-se mudas de abacaxizeiro 'Imperial' (Ananas comosus (L.) Merril) produzidas e multiplicadas in vitro, doadas pela Universidade Federal de Viçosa. Um termohigrômetro digital, modelo MT 240 MINIPA foi instalado no interior da casa de vegetação para determinar as variações de temperatura durante a realização do trabalho (Figura 1).

Figura 1. Variações das temperaturas máxima e mínima que ocorreram no interior da casa de vegetação durante o período de aclimatização e crescimento das mudas de abacaxizeiro 'Imperial'.

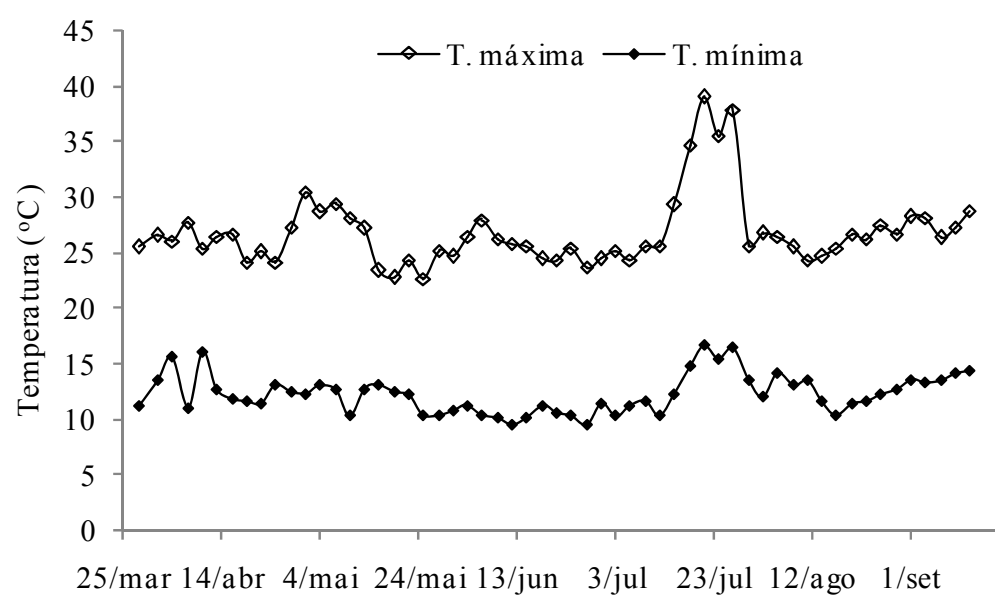

Fonte: Elaboração dos autores. 
Foi utilizado o esquema fatorial $2 \times 4$, sendo os fatores referentes às duas inoculações: mudas inoculada com o fungo $P$. indica e sem inoculação e quatro doses de herbicidas recomendadas para a cultura do abacaxizeiro, distribuídas no delineamento inteiramente casualizado, com três repetições, sendo a unidade experimental constituída por três mudas. Foram realizados três experimentos, utilizando-se diferentes herbicidas com as seguintes doses do produto comercial: $0 ; 1,5 ; 3,0$ e 6,0 $\mathrm{L} \mathrm{ha}^{-1}$ de ametryn; $0 ; 1,6 ; 3,2 ; 6,4 \mathrm{~L} \mathrm{ha}^{-1}$ de diuron e $0 ; 0,4$; 0,8 e $1,6 \mathrm{~L} \mathrm{ha}^{-1}$ de sulfentrazone.

O substrato utilizado para o plantio das mudas foi o Bioplant ${ }^{\circledR}$, com 3,2 $\mathrm{g} \mathrm{dm}^{-3}$ de $\mathrm{N} ; 0,94 \mathrm{~g} \mathrm{dm}^{-3}$

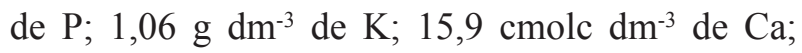
4,6 cmolc dm ${ }^{-3}$ de $\mathrm{Mg}$; 0,9 cmolc dm ${ }^{-3}$ de $\mathrm{Al}^{3+} ; 5,8$ cmolc $\mathrm{dm}^{-3}$ de $\mathrm{H}+\mathrm{Al} ; 23$ cmolc $\mathrm{dm}^{-3}$ de soma de

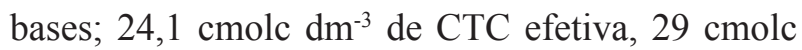
$\mathrm{dm}^{-3}$ de CTC potencial; $80 \%$ de saturação por bases;

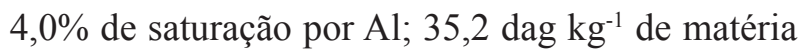
orgânica, o qual foi previamente autoclavado, durante uma hora, a $180^{\circ} \mathrm{C}$. Após a autoclavagem, foi realizado o enchimento dos sacos de polietileno com capacidade $0,1 \mathrm{dm}^{3}$.

A aplicação dos herbicidas foi feita antes do plantio das mudas utilizando-se um pulverizador com pressão constante de 3 bar, equipado com barra com dois bicos TT11002, espaçados de 0,5 $\mathrm{m}$. O volume preparado de cada dose foi definido mediante um teste em branco, a partir do volume de água utilizado e a distância percorrida para pulverizar os vasos de cada tratamento.

A inoculação com o fungo $P$. indica foi feita no momento do plantio, utilizando-se discos de micélio contendo estruturas fúngicas de $5 \mathrm{~mm}$ de diâmetro retirado da borda da colônia, com o objetivo de padronizar a quantidade de hifas adicionadas em cada recipiente.

Para o plantio, as mudas de abacaxizeiro foram retiradas do meio de cultura, lavadas, medidas, pesadas, padronizando-se o tamanho entre 5-6 cm de altura e massa de 20-25 g. Após o plantio em casa de vegetação, as mudas passaram por um período de aclimatização durante dois meses, mantidas cobertas com $50 \%$ de sombreamento e frequência e tempo de irrigação programada para um sistema automatizado para assegurar a umidade e evitar a desidratação das mudas.

Após o período de aclimatização, as mudas de todos os tratamentos receberam uma solução preparada com $10 \mathrm{mg} \mathrm{L}^{-1}$ de $\mathrm{N}$ e $1,85 \mathrm{mg} \mathrm{L}^{-1}$ de $\mathrm{K}$, via fertirrigação, uma vez por semana, até o final do experimento. Não foi feita adição de $P$, considerando que o substrato utilizado continha em sua formulação $0,94 \mathrm{~g} \mathrm{dm}^{-3}$.

Aos 150 dias após o plantio, amostras de folhas foram retiradas secas em estufa, moídas em moinho tipo Willey e submetidas à análise química para a determinação dos teores de nutrientes. A análise dos teores de $\mathrm{P}$ e $\mathrm{K}$ foi efetuada a partir da digestão nítrico-perclórica, obtendo-se extratos para a determinação dos teores de $\mathrm{P}$ por colorimetria e $\mathrm{K}$ por fotometria de chama. $\mathrm{O} \mathrm{N}$ total foi determinado pelo método Kjeldhal após digestão sulfúrica, conforme descrito por Malavolta, Vitti e Oliveira (1997).

Para avaliar o crescimento das mudas determinou-se a altura da parte aérea, diâmetro da coroa, número de folhas por planta, área foliar e à área foliar específica, massa seca de parte aérea, número de perfilhos por planta e o comprimento do sistema radicular.

A determinação da altura da parte aérea foi obtida medindo-se do colo até o ápice e a do número de perfilhos e folhas foi feita por meio de contagem. O comprimento de raiz foi determinado medindo-se a raiz principal. A massa seca de parte aérea foi obtida a partir da separação do sistema radicular da parte área das mudas, cortando-se na inserção do colo e, em seguida, acondicionada em sacos de papel e colocada para secar em estufa com circulação forçada de ar, a $65^{\circ} \mathrm{C}$, até atingir massa constante, sendo mensurada em balança eletrônica com precisão de $0,001 \mathrm{~g}$. 
A área foliar foi determinada empregando-se a metodologia da massa de disco de área conhecida (BENINCASA, 2003). Para isso, retiraram-se das folhas de cada tratamentodiscos foliares com um furador cilíndrico de área conhecida. Esses discos e as folhas de onde foram retirados foram colocados para secar em estufa com circulação forçada de ar, a $65{ }^{\circ} \mathrm{C}$, em sacos individuais de papel para a determinação de sua massa. Aárea foliar foi calculada conforme a equação [AF $=$ (massa seca das folhas $\mathrm{x}$ área dos discos/ massa seca dos discos)]. Com base nesses dados, foi calculada a área foliar específica (AFE) $[\mathrm{AFE}=$ (área foliar/massa das folhas)], que relaciona a superfície da folha com amassa da própria folha, indicando a disponibilidade de área foliar em cada grama de folha.

Para avaliação da associação micorrízica foi realizada a análise da colonização retirando as plantas do substrato de cultivo e as raízes foram separadas e lavadas em água corrente e fixadas com formol-ácido acético (FAA). Para avaliar a colonização fragmentos de, aproximadamente, $1 \mathrm{~cm}$ de comprimento das raízes finas foram clarificadas com $\mathrm{KOH}(10 \%)$ e coradas com azul de tripano em lactoglicerol 0,05\% (PHILLIPS; HAYMAN, 1970) e com o auxílio de uma lupa Optech 40X a colonização radicular foi observada.

Os dados obtidos foram submetidos à análise de variância e à regressão polinomial para comparar a fluorescência da clorofila, o crescimento vegetativo e os teores de nutrientes das mudas nas condições estudadas. Fez-se o desdobramento da interação, independentemente de ter sido significativa, com o objetivo de estudar os efeitos das doses de herbicidas nas mudas inoculadas e não inoculadas. A escolha dos modelos foi baseada no potencial para explicar o fenômeno biológico, no coeficiente de determinação e na significância dos coeficientes de regressão, utilizando-se o teste " $t$ ", considerando $p \leq 0,05$ de probabilidade de erro. Para comparar mudas inoculadas, foi realizada comparação de médias, considerando $p \leq 0,05$ de probabilidade de erro, pelo teste de F.

\section{Resultados e Discussão}

$\mathrm{Na}$ análise de colonização do sistema radicular, verificou-se a associação do fungo $P$. indica com as raízes do abacaxizeiro na presença dos três herbicidas testados. O fungo colonizou as raízes das mudas cultivadas com a aplicação de todas as doses dos herbicidas. Esse comportamento evidencia que os herbicidas não interfiram na associação do $P$. indica com o abacaxizeiro. Alguns autores atribuem o crescimento microrganismos na presença de herbicidas devido ao fato destes servirem como fonte de carbono e energia (TIRONI et al., 2009). Entretanto, deve-se considerar as doses utilizadas em decorrência dos ingredientes inertes da formulação, adicionados como adjuvantes, que atuam isoladamente ou em combinação com o herbicida, pois já foi observado efeito tóxico sobre os microrganismos do solo com alteração do comportamento fisiológico (MASSENSSINI et al., 2008).

Os fungos micorrízicos têm apresentado comportamento diferenciado em relação às condições do meio de cultivo. No presente trabalho, a quantidade de fósforo do substrato utilizado para o plantio das mudas, de $0,94 \mathrm{~g} \mathrm{dm}^{-3}$, não influenciou na associação do fungo $P$. indica com as mudas de abacaxizeiro, apesar da disponibilidade de fósforo (P) no substrato de cultivo ser apontada como um dos fatores que afetam a colonização das raízes pelos fungos (MACHINESKI; BALOTA; SOUZA, 2011). evidenciando que o papel do P na regulação da simbiose não está bem esclarecido (SCHACHTMAN; REID; AYLING, 1998).

$\mathrm{O}$ resultado neste estudo pode ser atribuído a capacidade diferenciada dos fungos micorrízicos em colonizar as diferentes espécies, além disso, cultivares da mesma espécie também podem apresentar diferentes respostas à inoculação com determinadas espécies ou isolados fúngicos (DECLERCK et al., 1995). Essa especificidade foi observada em abacaxizeiro das cultivares Pérola e Smooth Cayenne, com associação da mistura de 
Glomus clarum e Gigaspora margarita em ambas as cultivares, enquanto o Glomus etunicatum apresentou maior colonização na cultivar Pérola (SANTOS et al., 2011).

Em relação aos teores de nutrientes, no cultivo com a aplicação do ametryn, as mudas inoculadas com o $P$. indica apresentaram incrementos de $43,7 \%, 53,4 \%$ e $35,1 \%$ nos teores de $\mathrm{N}, \mathrm{P}$ e $\mathrm{K}$, respectivamente, estimados com a dose média de 3,35 L ha-1. As mudas que não foram inoculadas não apresentaram diferenças significativas entre os teores de nutrientes (Figuras 2a, 2b e 2c).

Figura 2. Teores de nitrogênio (a), fósforo (b) e potássio (c), em mudas de abacaxizeiro 'Imperial' inoculadas com o fungo $P$. indica, em função das doses de Ametryn.
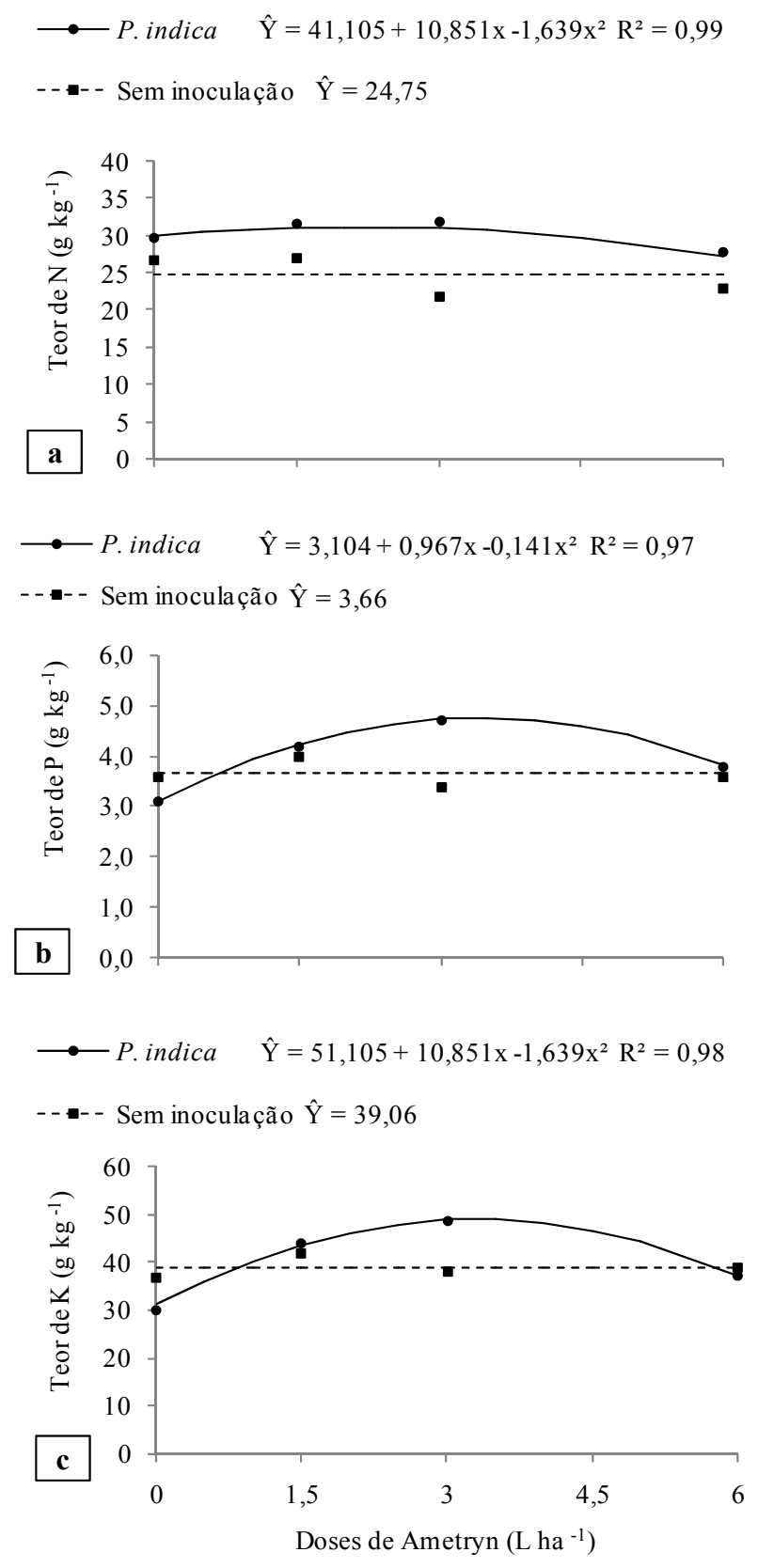

Fonte: Elaboração dos autores. 
As mudas associadas como $P$. indica apresentaram os melhores resultados, demonstrando que a associação com o fungo favoreceu a absorção de nutrientes com a presença do herbicida. Entretanto, a utilização de ametryn em doses elevadas pode ter influenciado a atividade do $P$. indica, evidenciando que os fungos micorrízicos atuam diferentemente em relação às variações das condições do meio de cultivo.

Nas mudas cultivadas com aplicação do herbicida diuron, a associação com $P$. indica favoreceu a absorção de P (Figura 2b), verificandose o incremento de $21,37 \%$, estimado com a dose de 4,04 $\mathrm{L} \mathrm{ha}^{-1}$, quando comparadas com as mudas do tratamento testemunha. Em relação aos teores de $\mathrm{N}$ e $\mathrm{K}$, foi observado decréscimo linear com aumento da dose do herbicida (Figuras 3a e 3c). Comportamento semelhante foi observado em abacaxizeiro inoculado com a mistura dos fungos G. clarum e Gigaspora margarita, na cultivar Pérola, tendo sido constatados menores teores de $\mathrm{P}$ e K (SANTOS et al., 2011). Os menores teores de N e K nas mudas associadas com $P$. indica podem ser atribuídos à alta demanda por esses nutrientes em função do maior crescimento dessas mudas.

Em relação ao sulfentrazone, nas mudas inoculadas com o $P$. indica foi observado incremento médio superior a $29 \%$ nos teores de $\mathrm{N}$ e $\mathrm{P}$ sob efeito da dose média de $0,8 \mathrm{~L} \mathrm{ha}^{-1}$ (Figuras $4 \mathrm{a}$ e 4b). Para os teores de $\mathrm{K}$, o incremento foi proporcional às doses aplicadas (Figura 4c), alcançando 28,8\% com a dose de 1,6 $\mathrm{L} \mathrm{ha}^{-1}$ em relação às mudas sem o herbicida.

Nas mudas que não foram inoculadas, observouse redução de 25,9\% nos teores de K com aplicação de 1,6 $\mathrm{L} \mathrm{ha}^{-1}$, comparadas com as mudas do tratamento testemunha (Figura 4c). Com a aplicação do herbicida, os teores de nutrientes foram maiores nas mudas associadas ao $P$. indica.

A associação das mudas de abacaxizeiro com o fungo $P$. indica favoreceu a absorção dos nutrientes, com acréscimos na absorção de $\mathrm{N}, \mathrm{P}$ e $\mathrm{K}$ nas mudas cultivadas com a aplicação de ametryn e sulfentrazone e de $\mathrm{P}$ com o diuron. Esse benefício para as mudas ocorre devido à geometria das hifas dos fungos micorrízicos em relação às raízes da planta, o que favorece a absorção de alguns nutrientes, incluindo o $\mathrm{P}$, devido a extensão das raízes formada pela micorrizosfera (CARDOSO et al., 2010). Essa característica é importante, visto que os solos tropicais, como os que ocorrem no território brasileiro, apresentam baixa produtividade, por apresentarem teores extremamente baixos de fósforo e alta capacidade de fixação desse nutriente. Em relação ao N, a sua ação é favorecer o transporte de solo para a raiz (JOHANSEN; JAKOBSEN; JENSEN, 1994).

Os bons resultados observados nas mudas inoculadas com o $P$. indica podem ser atribuídos à sua adaptação em diferentes ecossistemas, visto que esse fungo tem facilidade de cultivo em meio sintético (BAGDE; PRASADAND; VARMA, 2010). Isso tem contribuído para a sobrevivência e o crescimento das plantas, devido à maior capacidade de tolerar estresses biótico e abiótico e aumentar a absorção de água e de nutrientes (RODRIGUEZ; REDMAN, 2008).

Entretanto, nas condições que foi conduzida a produção das mudas deste trabalho, a presença do fungo micorrízico favoreceu a absorção de nutrientes pelas mudas em doses abaixo de 100\% da recomendada para a cultura do abacaxizeiro, visto que, com a aplicação da maior dose dos três herbicidas avaliados, os teores foram semelhantes às mudas sem a inoculação. Incremento nos teores de N e P, decorrentes da inoculação com o fungo $G$. etunicatum e a mistura de G. clarum e Gigaspora margarita em mudas de abacaxizeiro 'Smooth Cayenne', foram observados por Santos et al. (2011). Esse maior aporte de nutrientes ocorreu devido à expansão da zona de absorção da raiz com a presença dos fungos micorrízicos. A extensão da região de absorção das raízes pelos fungos micorrízicos tem favorecido a absorção de cerca de $80 \%$ de P, $25 \%$ de N e $10 \%$ de K (MARSCHNER; DELL, 1994). 
Entretanto, os benefícios dos fungos micorrízicos sobre a nutrição das espécie colonizadas dependem da combinação fungo-planta-condições do meio de cultivo, pois em algumas circunstâncias a melhoria na absorção de nutrientes pelas plantas colonizadas levam ao maior crescimento e, conseqentemente, maior utilização pelas mesmas, não sendo detectados no momento da análise.

Figura 3. Teores de nitrogênio (a), fósforo (b) e potássio (c), em mudas de abacaxizeiro 'Imperial' inoculadas com o fungo $P$. indica, em função das doses de diuron.
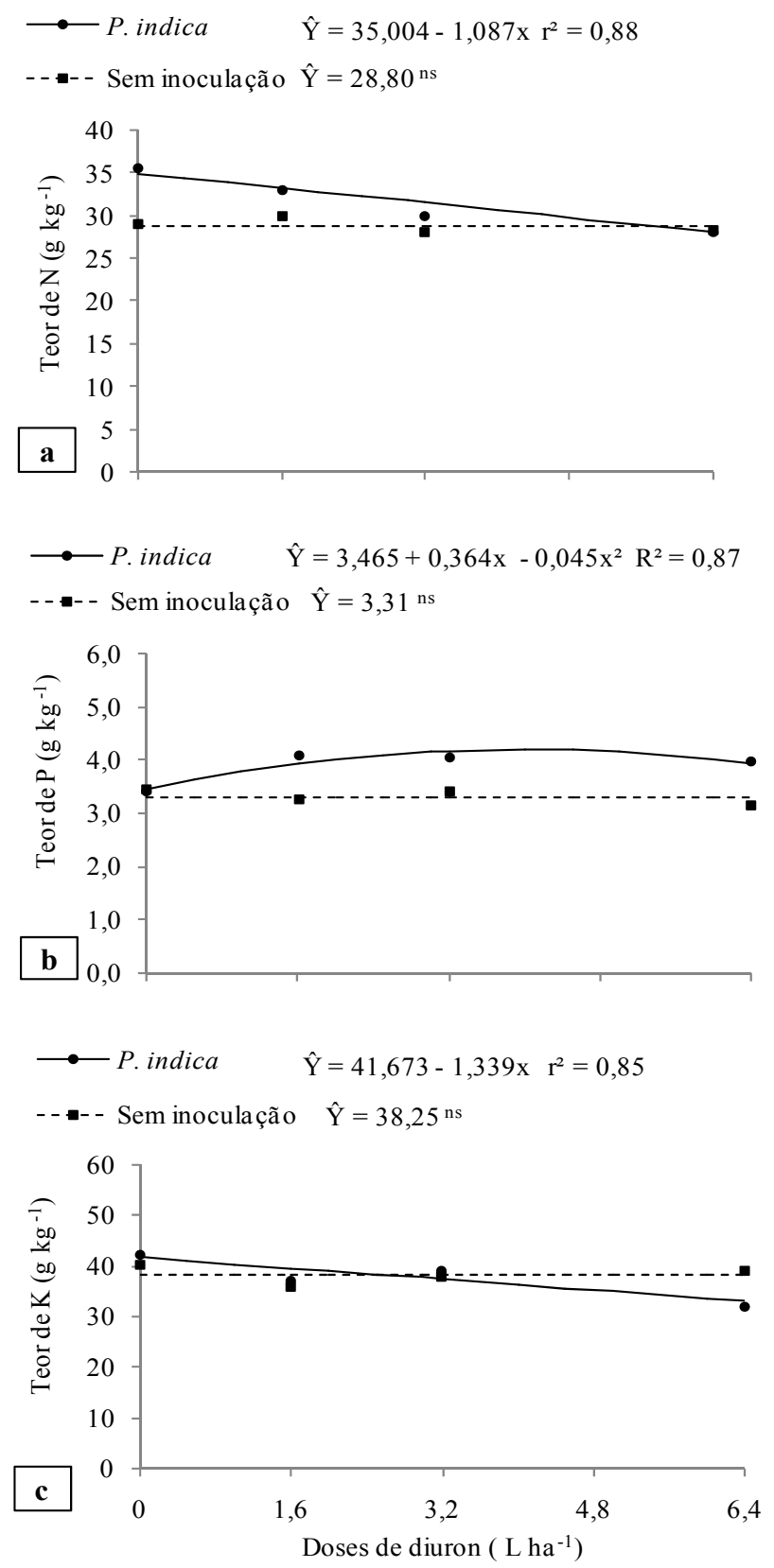

Fonte: Elaboração dos autores. 
Figura 4. Teores de nitrogênio (a), fósforo (b) e potássio (c), em mudas de abacaxizeiro 'Imperial' inoculadas com o fungo $P$. indica, em função das doses de sulfentrazone.
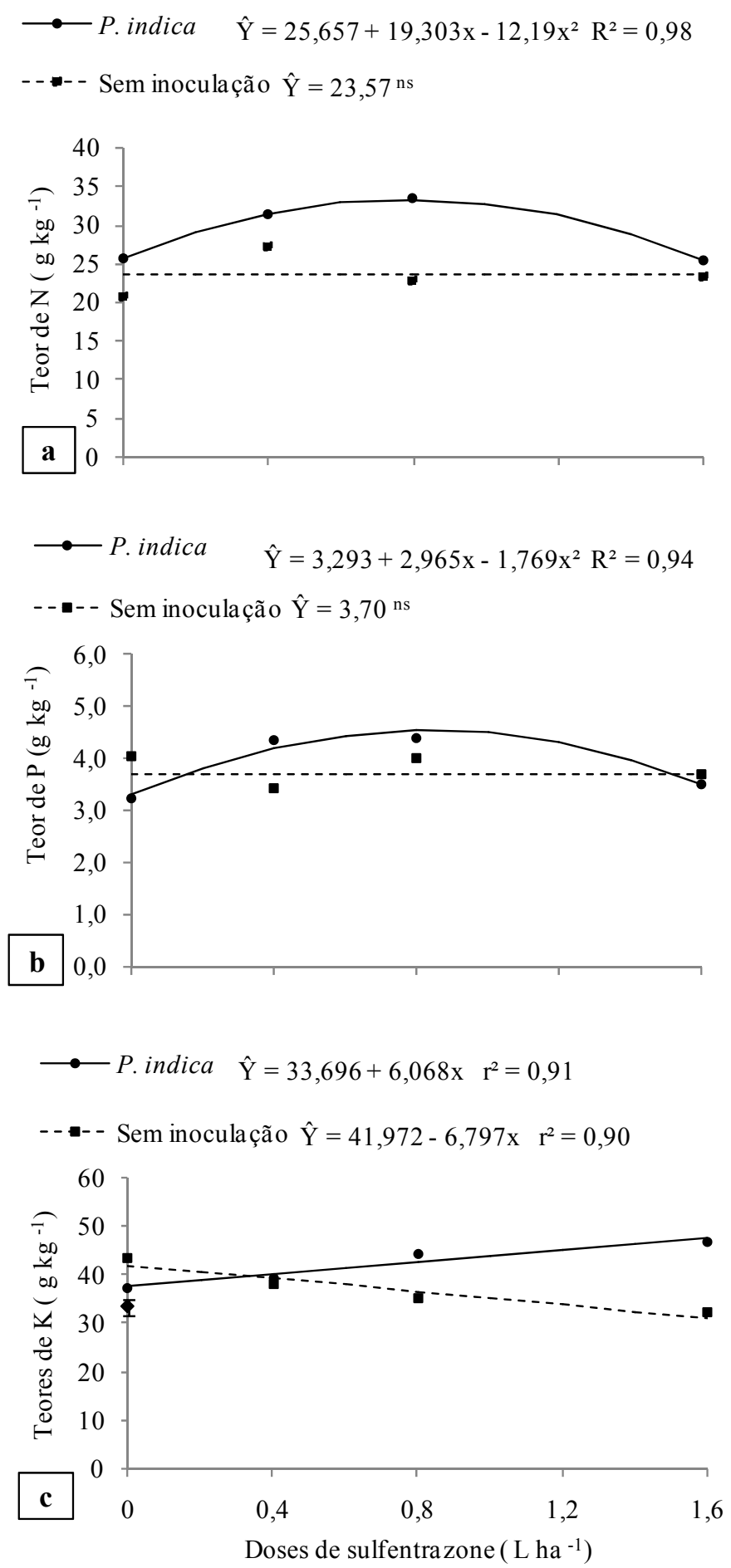

Fonte: Elaboração dos autores. 
Para o crescimento das mudas, observou-se no cultivo com a aplicação do ametryn (Figura 5), que as mudas inoculadas com o fungo $P$. indica apresentaram incrementos de $90,3 \%$, na altura; $89,09 \%$ no diâmetro da roseta; $44,99 \%$ no número de folhas; $192,61 \%$ na área foliar; $154,22 \%$ na área foliar específica; $128,72 \%$ na massa seca da parte aérea e $247,7 \%$ no número de perfilhos por planta, com a aplicação de6 $\mathrm{L} \mathrm{ha}^{-1}$ de ametryn, em relação do tratamento testemunha. Para o comprimento do sistema radicular, o acréscimo foi de 31,54\%, estimado com a dose de $3,1 \mathrm{~L} \mathrm{ha}^{-1}$, em relação ao sistema radicular das mudas sem o tratamento com o herbicida. Já as mudas que não foram inoculadas não apresentaram diferenças significativas entre as doses do herbicida aplicadas.

O comportamento no crescimento do sistema radicular em doses superiores a 3,1 $\mathrm{L} \mathrm{ha}^{-1}$ pode estar relacionado à alta exposição do fungo ao herbicida. Além disso, a aplicação direta de produtos formulados em microrganismos pode ter como efeito final a ação do ingrediente ativo e todos os aditivos do produto comercial (MALKONES, 2000).

Comparando-se o crescimento das mudas entre as inoculações, observou-se, de maneira geral, que as mudas não inoculadas com a aplicação do herbicida apresentaram menor tamanho. Esse comportamento sugere que as doses testadas do ametryn não prejudicaram o crescimento das mudas e que o acréscimo observado no crescimento das mudas inoculadas se deve à associação com o $P$. indica.

No cultivo com a aplicação do herbicida diuron, as mudas inoculadas com o $P$. indica apresentaram acréscimos na altura de 7,8\% (Figura 6a); no diâmetro da roseta de 14,1\%(Figura 6b); no número de folhas de 13,58\% (Figura 6c); na área foliar de 7,17\% (Figura 6d); na área foliar específica de 53,3\% (Figura 6e); na massa seca da parte aérea de 129,1\% (Figura 6f); no número de perfilhos por planta de $119,39 \%$ (Figura $6 \mathrm{~g}$ ) e de $17,39 \%$ no comprimento do sistema radicular (Figura 6h),em relação ao tratamento testemunha. Os incrementos em relação ao tamanho das mudas foram estimados com as doses que não ultrapassaram 3,72 $\mathrm{L} \mathrm{ha}^{-1}$.

Nas mudas que não foram inoculadas, observaram-se menor tamanho em altura, número de folhas, massa seca da parte aérea e comprimento do sistema radicular, quando comparadas com aquelas associadas com o fungo $P$ indica (Figura $6 \mathrm{a}$, 6c, $6 \mathrm{f}$ e $6 \mathrm{~h}$ ). Entretanto, com a aplicação de $100 \%$ da dose recomendada, as mudas apresentaram tamanhos semelhantes ao daquelas inoculadas. Esse comportamento indica que a aplicação da maior dose do herbicida pode ter interferido no crescimento do fungo.

Dessa forma, para a produção de mudas inoculadas com o fungo $P$. indica, a aplicação de doses elevadas do diuron pode ter reduzir a sua atividade, o que sugere que o seu uso deve ser moderado, visando manter a sobrevivência e o crescimento do fungo micorrízico. Por outro lado, a ação benéfica do herbicida, em doses moderadas, pode resultar da maior produção de isoflavonoides nas raízes, os quais podem favorecer a colonização micorrízica (SIQUEIRA; SAFIR; NAIR, 1991).

A diferença em relação ao crescimento das mudas inoculadas com o $P$. indica ocorreu devido à eficiência das diferentes espécies de fungos em promover a absorção de nutrientes pelas raízes. Isso porque as micorrízas são reconhecidas pelo efeito positivo que proporcionam no crescimento de plantas, pela melhoria na absorção de nutrientes, devido à expansão da zona de absorção da raiz (FREITAS; MARTINS; CARVALHO, 2006). 
Figura 5. Altura (a), diâmetro da coroa (b), número de folhas (c), área foliar (d), área foliar específica (e), massa seca da parte aérea (f), número de perfilhos por planta (g) e comprimento do sistema radicular (h) de mudas de abacaxizeiro 'Imperial' inoculadas com o fungo $P$. indica, em função das doses ametryn, aos 150 dias após o plantio.
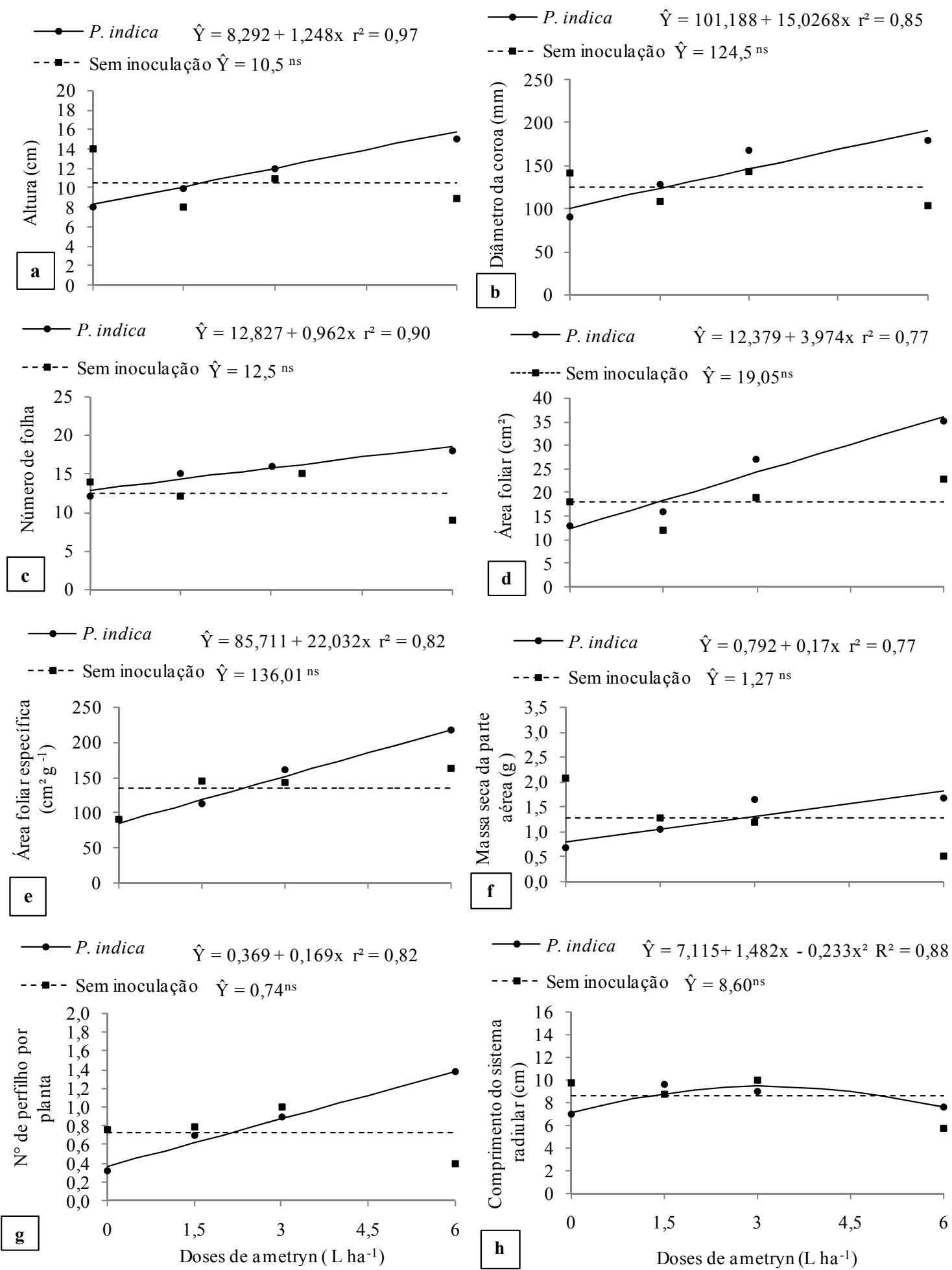

Fonte: Elaboração dos autores. 
Figura 6. Altura (a), diâmetro da roseta (b), número de folhas (c), área foliar (d), área foliar específica (e), massa seca da parte aérea (f), número de perfilhos por planta (g) e comprimento do sistema radicular (h), em mudas de abacaxizeiro 'Imperial'inoculadas com o fungo $P$. indica, em função das doses de diuron, aos 150 dias após o plantio.
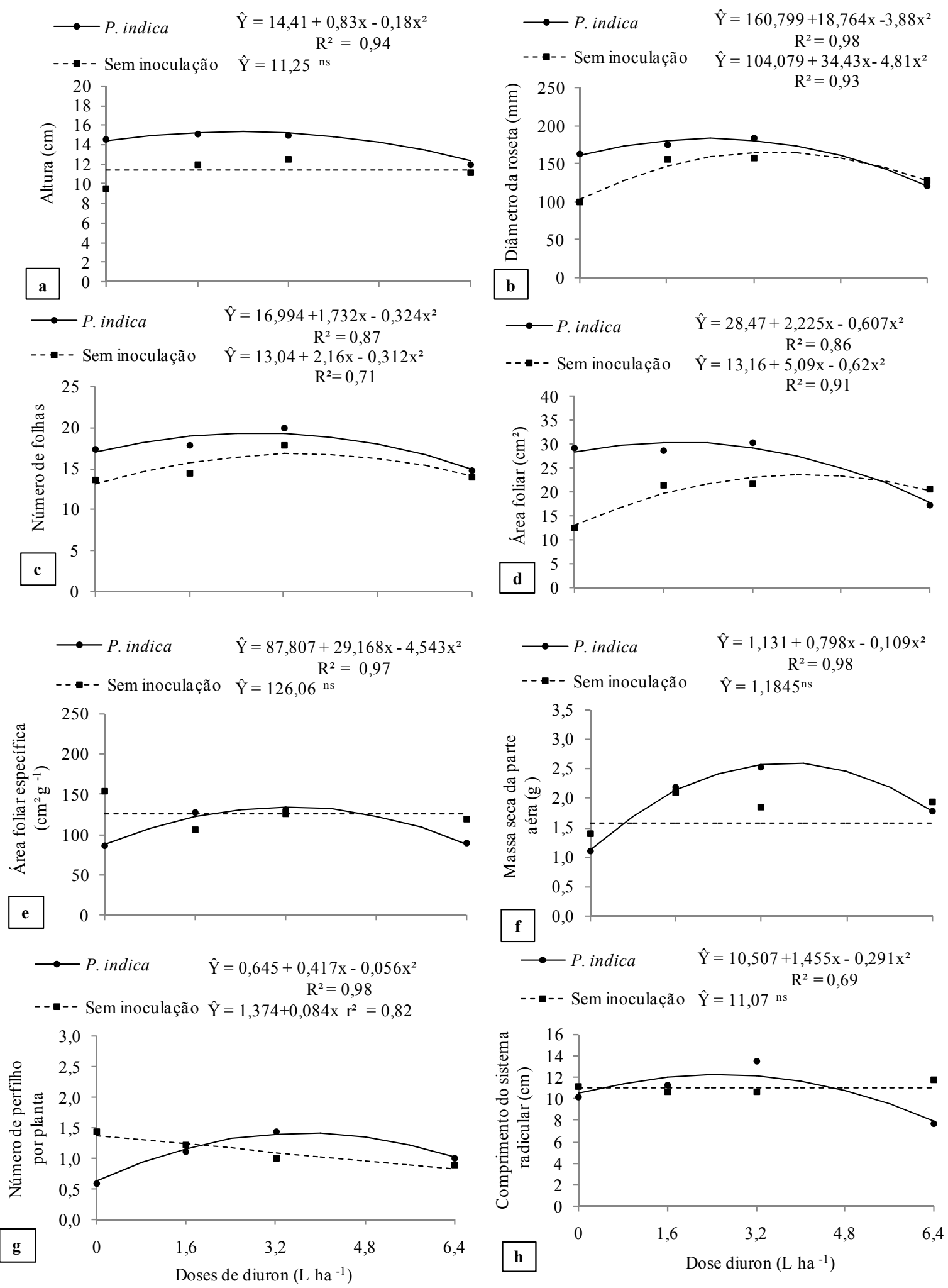

Fonte: Elaboração dos autores. 
Quanto ao crescimento das mudas cultivadas com a aplicação do sulfentrazone, naquelas associadas com o fungo $P$. indica verificaram-se incrementos de $33,8 \%$ na altura (Figura $7 \mathrm{a}$ ), de $63,17 \%$ no diâmetro da roseta (Figura $7 b$ ), de 16,49\% no número de folhas (Figura 7c), de 112,36\% na área foliar (Figura 7d), de $102,5 \%$ na massa seca da parte aérea (Figura $7 f$ ) e de 27,4\% no comprimento do sistema radicular (Figura $7 \mathrm{~h}$ ), estimados com a dose média de $0,74 \mathrm{~L} \mathrm{ha}^{-1}$. Em relação à área foliar específica e ao número de perfilhos por planta, observou-se decréscimo linear em função do aumento da dose do herbicida (Figuras 7 e e $7 \mathrm{~g}$ ). A área foliar específica relaciona a área da folha com a sua massa, o que indica que as mudas inoculadas sob ação do herbicida apresentaram folhas com maior massa por unidade área.

Em relação às mudas que não foram inoculadas, observaram-se redução linear de $43,3 \%$ na altura (Figura 7a), de 40,3\% no diâmetro da coroa (Figura $7 b$ ), de 31,17\% no número de folhas (Figura 7c) e de $56,6 \%$ na massa seca da parte área (Figura $7 \mathrm{f}$ ) com a aplicação de $1,6 \mathrm{~L} \mathrm{ha}^{-1}$ de sulfentrazone, comparadas àquelas do tratamento testemunha.

Os resultados observados evidenciaram que com a aplicação de doses elevadas do herbicida sulfentrazone interferência na atividade do fungo $P$. indica e no crescimento das mudas. Entretanto, nas doses menores, as mudas inoculadas apresentaram crescimento superior, quando comparadas às sem inoculação, enquanto sem a associação, o tamanho das mudas foi menor a medida que as doses foram aumentadas, possivelmente, por reduzir a eficiência do fotossistema II nas mudas de abacaxizeiro 'Imperial' (CRUZ et al., 2014), o que evidencia que a eficiência da associação micorrízica é dependente das condições do meio, além do genótipo da planta e da espécie do fungo, ocasionando em algumas situações menor crescimento das mudas. Isso foi verificado por Santos et al. (2011) com a associação de fungos micorrízicos em mudas de abacaxizeiro 'Smooth Cayenne' e 'Pérola. Os autores verificaram que a colonização proporcionou baixo crescimento vegetal, podendo até chegar a atingir uma condição de parasitismo, quando o balanço energético se torna desfavorável à planta.
No presente trabalho, quando não foi feita a aplicação do herbicida algumas características de crescimento das mudas foram maiores nas mudas não inoculadas, o que pode ter ocorrido pela presença do fungo, visto que estes podem receber mais de $10 \%$ dos fotossintatos produzidos pela planta hospedeira (MAIA; SILVEIRA; CAVALCANTE, 2005) ou, mesmo, pelo fato de essas mudas terem emitido maior número de perfilhos por planta (Figura $7 \mathrm{~g}$ ), o que demanda alta utilização de suas reservas.

Além disso, a maior dose utilizada do herbicida foi prejudicial ao crescimento das mudas, o que pode estar relacionado com crescimento do fungo porque, provavelmente, nesse meio de cultivo teve maior crescimento e passou a apresentar maior demanda energética. Isso pode levar a uma possível condição de estresse, de forma que parte da energia disponível ao organismo é despendida para manter mecanismos celulares e bioquímicos de tolerância, em detrimento do crescimento, reduzindo o coeficiente de rendimento microbiano (SCHIMEL; BALSER; WALLENSTEIN, 2007).

De maneira geral, nos três cultivos, a inoculação com fungo P.indica favoreceu o crescimento das mudas de abacaxizeiro 'Imperial'. Resultados semelhantes em relação ao crescimento de mudas de abacaxizeiro micropropagadas com a inoculação com Glomus claroideum foram observados por Gutiérrez-Oliva et al. (2009), que obtiveram maior número de folhas e matéria seca nas mudas. Essas características são importantes para a formação de mudas, pois, quanto maior o número de folhas, mais rapidamente elas alcançam o tamanho adequado para o plantio no campo. Para o abacaxizeiro, uma muda pode ser considerada adequada para o plantio definitivo quando atingir a altura mínima de $25 \mathrm{~cm}$. Quando as mudas são formadas por micropropagação, para atingir esse tamanho, elas podem demorar de 13 a 18 meses, sendo necessários, para a aclimatização e o crescimento em casa de vegetação, de 6 a 10 meses (BARROSO et al., 2003). 
Figura 7. Altura (a), diâmetro da coroa (b), número de folhas (c), área foliar (d), área foliar específica (e), massa seca da parte aérea (f), número de perfilhos por planta $(\mathrm{g})$ e comprimento do sistema radicular $(\mathrm{h})$ de mudas de abacaxizeiro 'Imperial' inoculadas com o fungo $P$. indica, em função das doses sulfentrazone, aos 150 dias após o plantio.
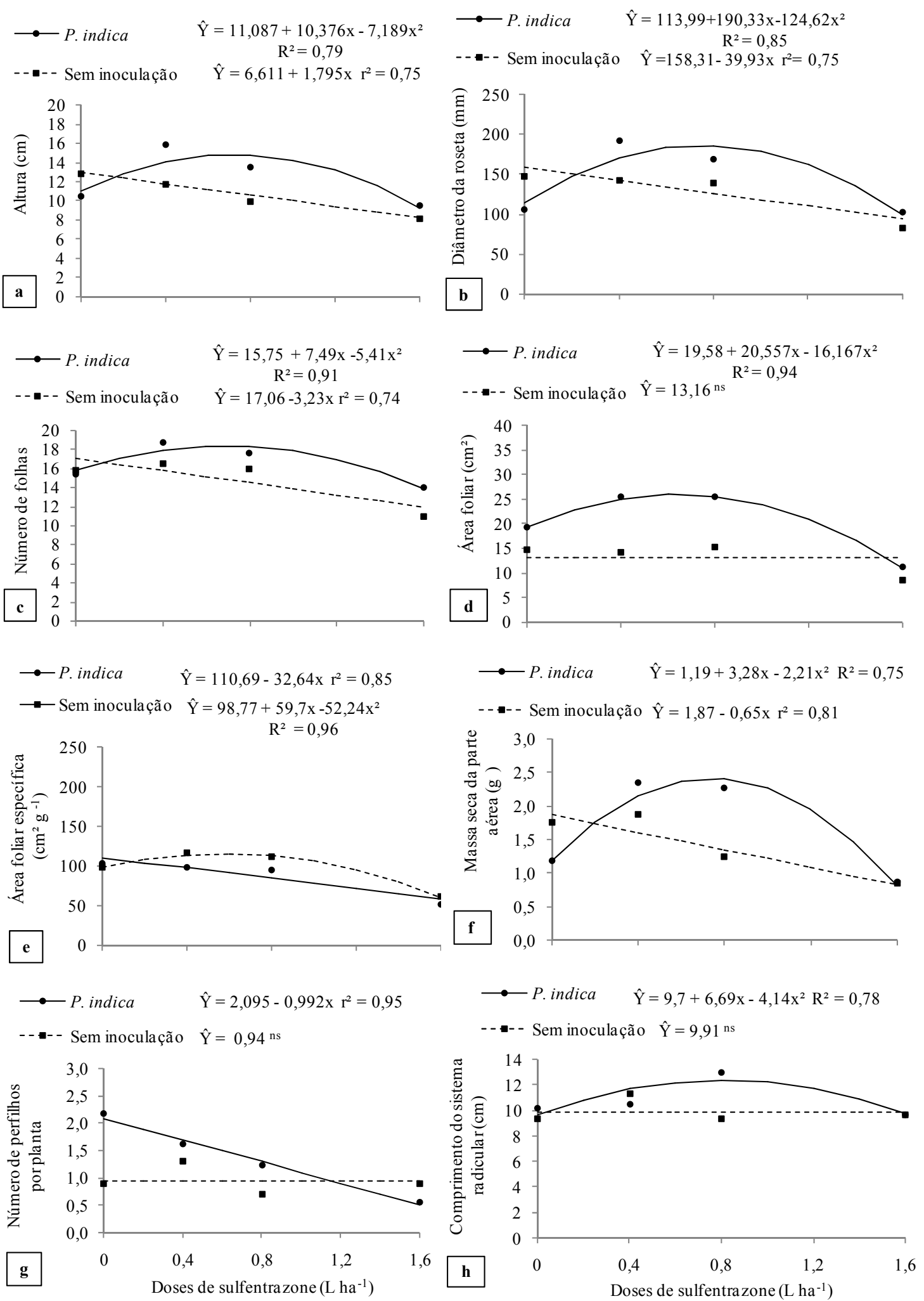

Fonte: Elaboração dos autores. 
Os resultados obtidos evidenciam que a associação com o fungo $P$. indica pode antecipar esse período, pois, com cinco meses, as mudas inoculadas alcançaram altura entre 13,84 a 15,78 cm, no cultivo com aplicação de emetryn; de 15,3 e 18,09 cm (Figura 5a), com aplicação de diuron (Figura 6a) e de 14,83 a 16,8 cm (Figura 7a), com a aplicação de sulfentrazone. Essa uma característica importante para reduzir os custos, pois o período de permanência no viveiro eleva sobremaneira o custo de produção das mudas (SANTOS et al., 2011).

\section{Conclusões}

Foi observada a associação do $P$. indica com as mudas de abacaxizeiro 'Imperial' nos cultivos com a aplicação de todos os herbicidas.

A associação com o $P$. indica favoreceu a maior absorção de nutrientes pelas mudas de abacaxizeiro 'Imperial'.

As mudas de abacaxizeiro 'Imperial' associadas com o fungo Piriformospora indica apresentaram maior crescimento.

A aplicação dos herbicidas em doses elevadas interferiu no crescimento e na absorção de nutrientes pelas mudas de abacaxizeiro micorrizadas.

\section{Referências}

ANJOS, E. C. T.; CAVALCANTE, U. M. T.; SANTOS, V. F.; MAIA, L. C. Produção de mudas de maracujazeirodoce micorrizadas em solo desinfestado e adubado com fósforo. Pesquisa Agropecuária Brasileira, Brasília, v. 40, n. 4, p. 345-351, 2005.

BAGDE, U. S.; PRASADAND, R.; VARMA, A. Review: interaction of mycobiont: Piriformospora indica with medicinal plants and plants of economic importance. African Journal of Biotechnology, Victoria Island, v. 9, n. 54, p. 9214-9226, 2010.

BARROSO, P. A. V.; MOURA, G. E. D. D.; BRITO, L. K. F.; MARTINS, C. P.; MACEDO, C. E. C.; LOPES, D. B.; ALOUFFA, M. A. I. Efeito do cultivo in vitro na presença de $\mathrm{NaCl}$ em plantas de abacaxizeiro na fase de aclimatação. Revista Brasileira de Engenharia Agrícola e Ambiental, Campina Grande, v. 7, n. 3, p. 473-477, 2003.

BENINCASA, M. M. P. Análise de crescimento de plantas: noções básicas. Jaboticabal: FUNEP, 2003. 42 p.

CARDOSO, E. J. B. N.; CARDOSO, I. M.; NOGUEIRA, M.A.; BARRETA, C. R. D. M.; PAULA, A. M. Micorrizas arbusculares na aquisição de nutrientes pelas plantas. In: SIQUEIRA, J. O.; SOUZA, F. A.; CARDOSO, E. J. B. N.; TSAI, S. M. Micorrizas: 30 anos de pesquisa no Brasil. Lavras: Editora UFLA, 2010. p. 153-214.

CAVALCANTE, U. M. T.; MAIA, L. C.; COSTA, C. M. C.; CAVALCANTE, A. T.; SANTOS, V. F. Efeito de fungos micorrízicos arbusculares, da adubação fosfatada e da esterilização do solo no crescimento de mudas de maracujazeiro amarelo. Revista Brasileira de Ciência do Solo, Viçosa, MG, v. 26, n. 4, p. 1099-1106, 2002.

CRUZ, L. I. B.; CRUZ, M. C. M.; FERREIRA, E. A.; CASTRO, G. D. M.; ALMEIDA, M. O. Eficiência quântica do fotossistema ii de mudas de abacaxizeiro 'Imperial' em resposta a associação com Piriformospora indica e herbicidas. Revista Brasileira de Fruticultura, Jaboticabal, v. 36, n. 4, p. 794-804, 2014.

DECLERCK, S.; FRANCO, A. A.; CAMPELLO, E.; FARIA, S. M.; SILVA, E. M. Leguminosas florestales: aspectos relacionados con sunutrición y uso em la recuperación de suelos degradados. Bosque, Valdivia, v. 16, n. 1, p. 121-127, 1995.

DUKE, S. O.; LYDON, J.;BECERRIL, J. M.; SHERMAN, T. D.; LEHNEN JÚNIOR, L. P.; MATSUMOTO, H. Protoporphyrinogen oxidase inhibiting herbicides. Weed Science, Boston, v. 39, n. 3, p. 465-473, 1991.

FAYEZ, K. A. Action of photosynthetic diuron herbicide on cell organelles and biochemical constituents of the leaves of two soybean cultivars. Pesticide Biochemistry Physiology, San Diego, v. 66, n. 2, p. 105-115, 2000.

FREITAS, M. S. M.; MARTINS, M. A.; CARVALHO, A. J. C. Crescimento e composição da menta em resposta à inoculação com fungos micorrízicos arbusculares e adubação fosfatada. Horticultura Brasileira, Brasília, v. 24, n. 1, p. 11-16, 2006.

GUTIÉRREZ-OLIVA, V. F.; ABUD-ARCHILA, M. F. A.; ALVAREZ, S. J. D.; GUTIÉRREZ-MICELI, F. A. Influencia de los hongos micorrízicos arbusculares sobre el crecimiento de vitro plántulas de piña (Ananas comosus (L.) Merr.) con diferentes niveles de fósforo. Gayana Botánica, Concepción, v. 66, n. 1, p. 1-9, 2009.

JOHANSEN, A.; JAKOBSEN, I.; JENSEN, E. S. Hyphal $\mathrm{N}$ transport by a vesicular-arbuscular mycorrhizal fungus associated with cucumber grown at three nitrogen levels. Plant and Soil, Dordrecht, v. 160, n. 1, p. 1-9, 1994. 
MACHINESKI, O.; BALOTA, E. L.; SOUZA, J. R. P. Resposta da mamoneira a fungos micorrízicos arbusculares e a níveis de fósforo. Semina: Ciências Agrárias, Londrina, v. 32, p. 1855-1862, 2011. Suplemento 1.

MAIA, L. C. B.; MAIA, V. M.; LIMA, M. H. M.; ASPIAZÚ, I.; PEGORARO, R. F. Growth, production and quality of pineapple in response to herbicide use. Revista Brasileira de Fruticultura, Jaboticabal, v. 34, n. 3, p. 799-805, 2012.

MAIA, L. C.; SILVEIRA, N. S. S.; CAVALCANTE, U. M. T. Interaction between arbuscular fungi and root pathogens. In: RAI, M. K. Handbook of microbial biofertilizers. New York: Haworth Press, 2005. p. 325351.

MALAVOLTA, E.; VITTI, G. C.; OLIVEIRA, S. A. de. Avaliação do estado nutricional das plantas: princípios e aplicações. 2.ed. Piracicaba: POTAFOS, 1997. 319 p.

MALKONES, H. P. Comparison of the effects of differently formulated herbicides on soil microbial activities a review. Journal of Plant Diseases and Protection, Braunschweig, v. 8, n. 5, p. 781-789, 2000.

MARSCHNER, H.; DELL, B. Nutrient uptake in mycorrhizal symbiosis. Plant and Soil, Dordrecht, v. 159, n. 1, p. 89-102, 1994.

MARTINS, M. A.; GONÇALVES, G. F.; SOARES, A. C. F. Efeito de fungos micorrízicos arbusculares associados a compostos fenólicos, no crescimento de mudas de mamoeiro. Pesquisa Agropecuária Brasileira, Brasília, v. 35, n. 7 , p. $1465-1471,2000$.

MOREIRA, F. M. S.; SIQUEIRA, J. O. Microbiologia e bioquímica do solo. 2. ed. Lavras: Editora UFLA, 2006. $729 \mathrm{p}$.

MASSENSSINI, A. M.; COSTA, M. D.; REIS, M. R.; SILVA, A. A. Atividade de isolados bacterianos solubilizadores de fosfato na presença de formulações comerciais de glyphosate. Planta Daninha, Viçosa, MG, v. 26 , n. 4 , p. 815-823, 2008.
OELMÜLLER, R.; SHEREMETI, I.; TRIPATHI, S.; VARMA, A. Piriformospora indica, a cultivable root endophyte with multiple biotechnological application. Symbiosis, Springer International Publishing, Cham, v. 49, n. 1, p. 1-17, 2009.

PHILLIPS, J. M.; HAYMAN, D. S. Improved procedures for clearing roots and staining parasitic and vesiculararbuscular mycorrhizal fungi for rapid assessment of infection. Transactions of the British Mycological Society, Londres, v. 55, n. 1, p. 157-160, 1970.

RODRIGUEZ, R.; REDMAN, R. More than 400 million years of evolution and some plants still can't make it on their own: plant stress tolerance via fungal symbiosis. Journal of Experimental Botany, Oxford, v. 59, n. 5, p. 1109-1114, 2008.

ROSA, D. D.; BASSETO, M. A.; CAVARIANI, C.; FURTADO, E. L. Efeito de herbicidas sobre agentes fitopatogênicos. Acta Scientiarum. Agronomy, Maringá, v. 32, n. 3, p. 379-383, 2010.

SANTOS, P. C.; FREITAS, M. S. M.; FREITAS, S. J.; SILVA, M. P. S.; BERILLI, S. S. Fungos micorrízicos no crescimento e nutrição de rebentos oriundos de coroa de abacaxi. Revista Brasileira Fruticultura, Jaboticabal, v.33, p. 658-665, 2011. Número Especial.

SCHACHTMAN, D. P.; REID, R. J.; AYLING, S. M. Phosphorus uptake by plants: from soil to cell. Plant Physiology, Rockville, v. 116, n. 2, p. 447-453, 1998.

SCHIMEL, J. P.; BALSER, T. C.; WALLENSTEIN, M. Microbial stress-response physiology and its implications for ecosystem function. Ecology, New York, v. 88, n. 6, p. 1386-1394, 2007.

SIQUEIRA, J. O.; SAFIR, G. R.; NAIR, M. G. Stimulation of vesicular-arbuscularmycorrhiza formation and growth of white clover by flavonoid compounds. New Phytologist, Cambridge, v. 118, n. 1, p. 87-93, 1991.

TIRONI, S. P.; BELO, A. F.; FIALHO, C. M. T.; GALON, L.; FERREIRA, E. A.; SILVA, A. A.; COSTA, M. D.; ARBOSA, M. H. P. Effect of Herbicides on Soil Microbial Activity. Planta Daninha, Viçosa, MG, v. 27, p. 995-1004, 2009. Número Especial. 